\title{
Adubação fosfatada em mudas de bananeira 'Prata anã'(AAB), cultivadas em dois Latossolos
}

\author{
José Tadeu Alves da Silva ${ }^{1}$, Inêz Pereira Silva², Rosimeire Dantas Pereira ${ }^{3}$
}

\section{RESUMO}

As informações relacionadas com os efeitos do fósforo sobre o desenvolvimento de bananeiras ainda são poucas. Os objetivos deste trabalho foram avaliar os efeitos da aplicação de fósforo sobre o desenvolvimento de mudas de bananeira "Prata Anã", cultivadas em Latossolo Vermelho (LV) e Latossolo Vermelho- Amarelo (LVA, e determinar o nível crítico de fósforo. Os tratamentos foram distribuídos em um delineamento inteiramente casualizado, em esquema fatorial 8 x 2, com três repetições. Os fatores corresponderam a oito doses de fósforo $(0 ; 50 ; 100 ; 150 ; 300 ; 450 ; 600 ; 750$ mg.dm ${ }^{-3}$ ) e dois tipos de solos, respectivamente. A produção de matéria seca das mudas de bananeira aumentou com as aplicações de fósforo nos solos. Os níveis críticos de fósforo nos solos LV e LVA foram 18,9 e 40,2 mg dm ${ }^{-3}$, respectivamente e, nas folhas das mudas cultivadas no LV e LVA os níveis críticos de fósforo foram 0,20 e $0,31 \mathrm{dag} \mathrm{kg}^{-1}$, respectivamente. $\mathrm{O}$ fósforo foi utilizado com maior eficiência pelas mudas de bananeira cultivadas no LV.

Palavras-chave: Musa sp., nutrição, capacidade tampão de fósforo.

\section{ABSTRACT}

\section{Phosphorus fertilization in banana 'Prata anã' (AAB) cultivated in two latosols}

Data on the effect of phosphorus on the development of banana are scarce. The objectives of this work were to evaluate the effect of the application of phosphorus on the development of banana "Prata Anã" growing in a Red Latosol (RL) and a Red-Yellow Latosol (RYL), as well as to determine the phosphorus critical level. The treatments were arranged in a randomized design, using a 8 x 2 in factorial arrangement, with three replications. The factors corresponded to eight phosphorus doses $\left(0 ; 50 ; 100 ; 150 ; 300 ; 450 ; 600 ; 750 \mathrm{mg} \cdot \mathrm{dm}^{-3}\right)$ and the two soil types. The dry mass production of banana seedlings increased with phosphorus application to both soils. Phosphorus soil critical levels in RL and RYL were 18.9 and $40.2 \mathrm{mg} \mathrm{dm}^{-3}$, respectively. The phosphorus critical levels in the leaves of banana seedlings growing in RL and RYL were 0.20 and $0.31 \mathrm{dag} \mathrm{kg}^{-1}$, respectively. Phosphorus was used more efficiently by banana seedlings growing in RL.

Key words: Musa sp., nutrition, phosphorus buffer capacity.

\footnotetext{
Recebido para publicação em julho de 2010 e aprovado em dezembro de 2010

${ }^{1}$ Engenheiro-Agrônomo, Doutor. EPAMIG, Fazenda Experimental de Montes Claros, 39.401-046, Montes Claros, Minas Gerais, Brasil. josetadeu@epamig.br

2 Engenheira-Agrônoma. Universidade Federal de Lavras, Departamento de Ciência do Solo, Caixa Postal n 3.037, 37.200-000, Lavras, Minas Gerais, Brasil. inezps@yahoo.com.br

Graduanda no curso de Agronomia. UNIMONTES, Caixa Postal nº 12, 39.525-000, Nova Porteirinha, Minas Gerais, Brasil. rosimeire.dantas@yahoo.com.br
} 


\section{INTRODUÇÃO}

A bananeira, por ter um crescimento rápido, requer quantidades suficientes de nutrientes disponíveis no solo para seu desenvolvimento normal, sendo assim, a adubação é um fator de grande importância e deve ser balanceada, para evitar distúrbios nutricionais e, consequentemente, redução de produtividade.

O cultivo da bananeira na região norte de Minas predomina em áreas de ocorrência de Latossolos de texturas variáveis. Um dos maiores problemas desses solos está nos níveis extremamente baixos de fósforo disponível. Aliada a esta pobreza natural em fósforo, tem-se a alta capacidade de adsorção desse elemento, em consequência da acidez e dos elevados teores de óxido de ferro e de alumínio presentes nos Latossolos.

Alguns trabalhos de pesquisa têm procurado relacionar os atributos físicos dos solos com os níveis críticos de fósforo no solo e na parte aérea das plantas (Silva, 1990; Bonfim et al., 2004). De acordo com Novais et al. (2007), o nível crítico de P no solo correlaciona-se com as características do solo que refletem a capacidade tampão de fósforo, como o fósforo remanescente, que é a medida da quantidade de fósforo que permanece em solução de equilíbrio, em resposta a uma concentração de fósforo adicionada ao solo. Quanto menor o valor do fósforo remanescente de determinado solo, maior é o seu potencial de adsorção de fósforo.

Nas regiões brasileiras produtoras de banana, as doses de fósforo utilizadas em plantios comerciais variam de 0 a $150 \mathrm{~kg}$ de $\mathrm{P}_{2} \mathrm{O}_{5} \mathrm{ha}^{-1}$ ano $^{-1}$, conforme os teores existentes no solo (Borges \& Oliveira, 2000). As condições de solo e clima e as exigências das diferentes variedades influenciam a necessidade de adubação da cultura.

Entre os macronutrientes, o fósforo é o menos exigido pela bananeira. De acordo com Hoffmann et al (2010), os nutrientes mais absorvidos pela bananeira são: $\mathrm{K}>\mathrm{N}>\mathrm{S}$ $>\mathrm{Mg}>\mathrm{Ca}>\mathrm{P}$. O fósforo está entre os nutrientes mais carentes nos solos brasileiros, pois, em geral, faz-se presente nos Latossolos em concentrações baixas e com alta proporção em formas químicas pouco assimiláveis pelas plantas (Novais \& Smyth, 1999).

Em trabalho realizado no norte de Minas Gerais, Silva et al. (2007) verificaram que os teores de fósforo disponíveis nos solos foram maiores em bananais de alta produtividade, quando comparados com os de baixa produtividade.

O fósforo é absorvido pelas plantas nas formas de $\mathrm{HPO}_{4}^{-2}$ ou $\mathrm{H}_{2} \mathrm{PO}_{4}^{-}$. Nos solos ácidos, há predomínio da forma $\mathrm{H}_{2} \mathrm{PO}_{4}^{-}$, isso em decorrência das reações de equilíbrio do fósforo no solo. Furtini Neto et al. (2001) relatam que o $\mathrm{pH}$ que favorece maior disponibilidade de fósforo está entre 6,0 e 6,5. Nessa faixa de pH, ocorre o equilíbrio entre as duas formas de fósforo absorvidas pelas plantas.
De acordo com Silva et al. (1999), a deficiência de fósforo na bananeira faz com que ocorra baixo desenvolvimento das plantas, reduzida formação de raízes, amarelecimento e retorcimento das folhas mais velhas, quebra de pecíolo e produção de cachos raquíticos, com irregularidade na maturação e frutos pouco saborosos.

Os objetivos deste trabalho foram avaliar os efeitos da aplicação de fósforo em dois Latossolos sobre o desenvolvimento de mudas de bananeira 'Prata Anã', cultivadas em casa de vegetação, e determinar os níveis críticos de fósforo.

\section{MATERIAL E MÉTODOS}

Amostras de Latossolo Vermelho de textura argilosa (LV) e de Latossolo Vermelho-Amarelo de textura média (LVA) foram coletadas na região do norte de Minas Gerais, na profundidade de 0 a $20 \mathrm{~cm}$. As amostras foram passadas em peneira de quatro milímetros de abertura, das quais foram retiradas subamostras que foram submetidas às análises química e granulométrica (Tabela 1).

Os tratamentos foram distribuídos em delineamento inteiramente casualizado, em esquema fatorial $8 \times 2$, correspondendo a oito doses de fósforo $(0 ; 50 ; 100$; 150; 300; 450; 600 e $750 \mathrm{mg} . \mathrm{dm}^{-3}$ ) e dois tipos de solos (LV e LVA), respectivamente, com três repetições. A fonte de fósforo foi o fosfato de potássio monobásico $\left(\mathrm{KH}_{2} \mathrm{PO}_{4}\right)$. Para que todos os vasos recebessem a mesma quantidade de $\mathrm{K}$ (944 $\left.\mathrm{mg} \mathrm{dm}^{-3}\right)$, aplicou-se $\mathrm{KCl}$ nos vasos proporcionalmente às doses de $\mathrm{KH}_{2} \mathrm{PO}_{4}$ recebidas. Assim, no tratamento com a maior dose de $\mathrm{P}$ não foi aplicado o $\mathrm{KCl}$, pois todo $\mathrm{K}$ foi suprido pelo $\mathrm{KH}_{2} \mathrm{PO}_{4}$ e no tratamento testemunha, onde não foi aplicado fósforo $\left(\mathrm{KH}_{2} \mathrm{PO}_{4}\right)$, todo $\mathrm{K}$ foi aplicado, utilizando-se o $\mathrm{KCl}$. Em todos os vasos, foi aplicada uma mistura de micronutrientes em solução (em mg vaso ${ }^{-1}: 15,0$ de zinco; 15,0 de cobre e 15,0 de boro). O calcário dolomítico foi aplicado somente no LVA para elevar a saturação de bases para $75 \%$.

As mudas de bananeira obtidas de culturas de tecido foram cultivadas em vasos contendo cinco $\mathrm{dm}^{3} \mathrm{do}$ solo previamente analisado. As mudas foram cultivadas durante 90 dias e, após esse período, foram avaliados a altura e o diâmetro do pseudocaule. As plantas foram cortadas rente ao solo, em seguida, realizou-se a separação das raízes das plantas do solo de cada vaso. As raízes e o pseudocaule foram secados e pesados, e as folhas foram secadas, pesadas, moídas, mineralizadas e analisadas. A mineralização foi realizada por digestão nitroperclórica. No extrato obtido, foi determinado o teor de fósforo, conforme metodologia descrita em Malavolta et al (1997). 
A massa seca da parte aérea das mudas foi calculada somando-se as massas secas do pseudocaule e das folhas. O fósforo disponível no solo foi determinado após o corte das mudas e separação das raízes das plantas do solo de cada vaso. O fósforo foi extraído do solo com o extrator Melich-1, na relação solo: solução de 1:10, conforme descrito por Braga (1980).

Os níveis críticos de fósforo no solo e nas folhas das mudas da bananeira foram estimados, substituindo-se as doses de fósforo que proporcionaram $90 \%$ do peso máximo da massa seca da parte aérea nas equações de regressão, ajustadas entre o teor de fósforo disponível no solo e nas folhas das mudas, com as doses de fósforo aplicadas nos solos. Os dados coletados foram submetidos a análises de variância e ajustes de regressões, conforme Alvarez V. (1994).

A eficiência de utilização de fósforo pelas mudas de bananeira foi calculada, utilizando-se a expressão proposta por Siddigi \& Glass (1981):

$\mathrm{E}=(\mathrm{MS})^{2} \mathrm{P}^{-1}$, em que:

$\mathrm{E}=$ eficiência de utilização de fósforo.

MS = peso médio de massa seca da parte aérea.

$\mathrm{P}=$ quantidade de fósforo acumulada.

\section{RESULTADOS E DISCUSSÃO}

Verificou-se que o diâmetro do pseudocaule e a altura das plantas aumentaram, com as doses de fósforo aplicadas, tanto no LV quanto no LVA (Figuras 1 e 2). As doses de fósforo aplicadas no $\mathrm{LV}$ para obter o diâmetro máximo $(3,57 \mathrm{~cm})$ e a altura máxima das mudas $(31,8 \mathrm{~cm})$ foram de 700 e $545 \mathrm{mg} \mathrm{dm}^{-3}$, respectivamente e, no LVA foram de 483 e $600 \mathrm{mg} \mathrm{dm}^{-3}$ para obter o diâmetro máximo $(3,09 \mathrm{~cm})$ e a altura máxima das mudas $(31,1 \mathrm{~cm})$, respectivamente.

Alguns trabalhos realizados com outras espécies têm encontrado efeitos da aplicação de fósforo no solo sobre o desenvolvimento das plantas. Prado et al (2005) verificaram efeitos das doses de fósforo aplicadas no solo sobre a altura e diâmetro do caule de mudas de maracujazeiro. As limitações na disponibilidade de fósforo no início do ciclo vegetativo podem resultar em restrições no desenvolvimento das plantas.

A massa da matéria seca da parte aérea das mudas aumentou com o aumento das doses de fósforo aplicadas no LV e LVA (Figura 3). As doses de fósforo para obter
90\% da massa da matéria seca máxima da parte aérea foram de 360 e $518 \mathrm{mg} \mathrm{dm}^{-3}$ para o LV e LVA, respectivamente. Verificou-se que a adubação fosfatada é de extrema importância para a bananeira, para que a planta, no seu

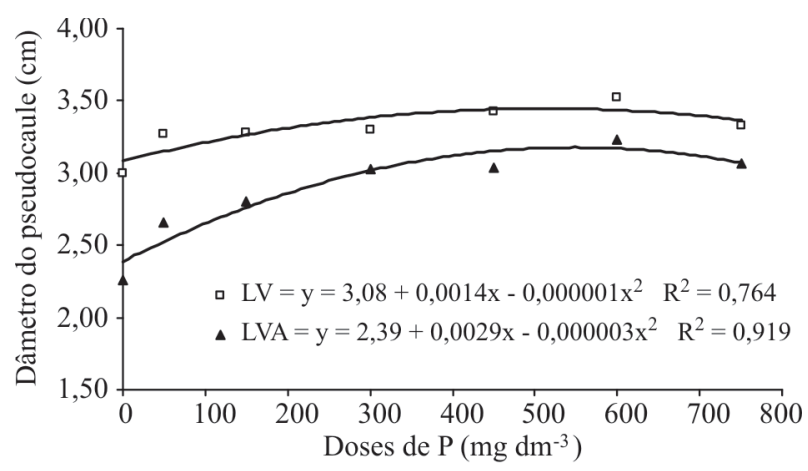

Figura 1 - Diâmetro do pseudocaule de mudas de bananeira 'Prata anã' em função de doses de fósforo aplicadas no LV e LVA.

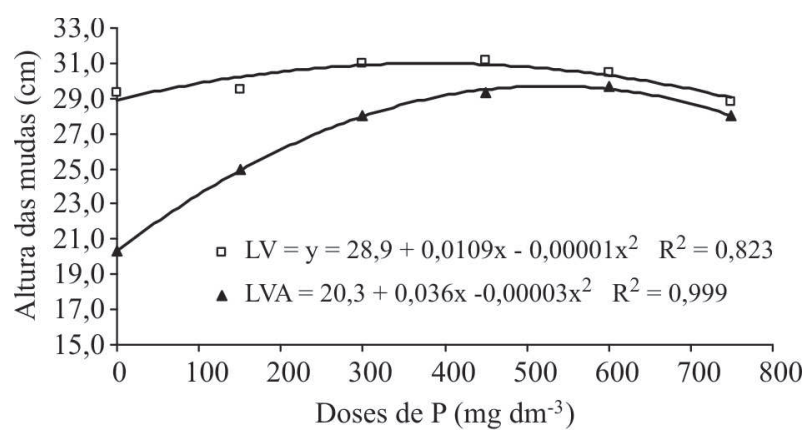

Figura 2 - Altura de mudas de bananeira 'Prata anã' em função de doses de fósforo aplicadas no LV e LVA.

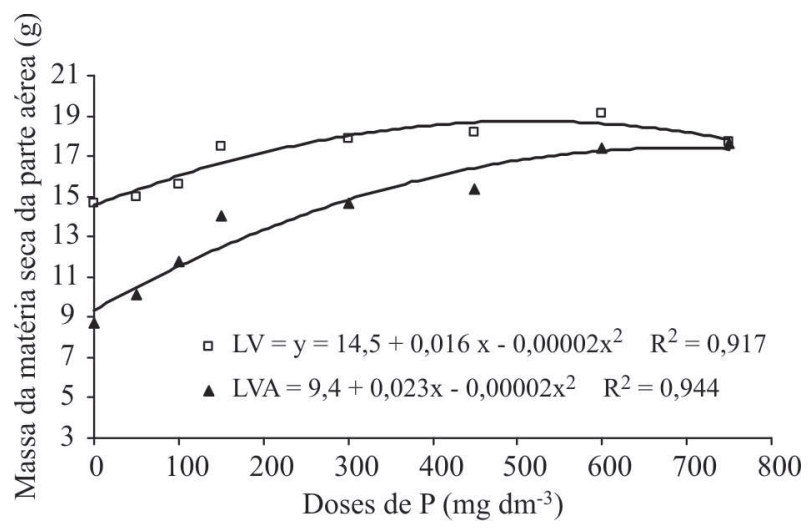

Figura 3 - Massa da matéria seca da parte aérea de mudas de bananeira Prata anã em função de doses de fósforo aplicadas no LV e LVA.

Tabela 1 Atributos químicos e granulometria dos solos. Nova Porteirinha - MG, 2010

\begin{tabular}{|c|c|c|c|c|c|c|c|c|c|c|c|c|}
\hline \multirow{2}{*}{ Solos } & \multirow{2}{*}{ pH } & ${ }^{2} \mathbf{P}$ & ${ }^{2} \mathbf{K}$ & $\mathbf{C a}$ & Mg & CTC & \multirow{2}{*}{$\begin{array}{l}\mathrm{V} \\
\%\end{array}$} & \multirow{2}{*}{$\frac{{ }^{1} \text { P-rem }}{\text { mg } L^{-1}}$} & ${ }^{3} \mathrm{MO}$ & Argila & Silte & Areia \\
\hline & & \multicolumn{2}{|c|}{$\mathrm{mg} \mathrm{dm}^{-3}$} & \multicolumn{3}{|c|}{$\mathrm{cmol}_{\mathrm{c}} \mathrm{dm}^{-3}$} & & & \multicolumn{4}{|c|}{ dag $\mathrm{kg}^{-1}$} \\
\hline $\mathrm{LV}$ & 6,1 & 3,3 & 128 & 6,5 & 1,6 & 11,0 & 78 & 18,4 & 2,4 & 50 & 29 & 21 \\
\hline LVA & 5,2 & 2,4 & 87 & 2,0 & 0,4 & 5,7 & 48 & 33,2 & 1,1 & 35 & 15 & 50 \\
\hline
\end{tabular}

${ }^{1}$ Fósforo remanescente. ${ }^{2}$ Extrator Melich-1. ${ }^{3} \mathrm{MO}$ : Matéria orgânica. 
estádio inicial, desenvolva-se com maior vigor, principalmente quando cultivada em solo com baixo teor de fósforo disponível. No trabalho realizado por Sousa et. al. (2000), não houve efeito da aplicação de doses crescentes de fósforo sobre a altura e a produção total de matéria fresca de mudas de bananeira "Mysore". De acordo com os autores, a ausência de resposta à aplicação de fósforo no solo foi graças ao teor desse nutriente, presente no substrato utilizado para produzir as mudas, ter sido suficiente para suprir as necessidades de fósforo destas.

As doses de fósforo aplicadas no LVA aumentaram linearmente a massa da matéria seca das raízes e, no $\mathrm{LV}$, a variação foi quadrática (Figura 4). A dose de fósforo para obter $90 \%$ da massa da matéria seca máxima das raízes $(29,0 \mathrm{~g})$ das mudas cultivadas no LV foi de $390 \mathrm{mg} \mathrm{dm}^{-3} \mathrm{de}$ fósforo. De acordo com Dechen \& Nachtigall (2007), em situações onde se aumenta o suprimento de fósforo no solo, de uma condição de deficiência até outra de adequada disponibilidade, ocorre a rápida formação e crescimento das raízes das plantas.

Verificou-se que os teores de fósforo disponível no solo (Figura 5) e nas folhas (Figura 6) aumentaram linearmente com o aumento das doses de fósforo aplicadas nos dois solos utilizados. O teor de fósforo nas folhas foi maior nas mudas de bananeira cultivadas no LVA de textura média. Diversos fatores influenciam a absorção de fósforo pelas plantas, entre esses fatores encontram-se as características físicas do solo, que refletem sua capacidade tampão de fósforo. Bedin et al. (2003) verificaram menores teores foliares de fósforo em plantas de soja desenvolvidas em solo com elevada capacidade tampão de fósforo e maiores teores no solo arenoso, com baixa capacidade tampão. Segundo os autores, esse aparente ajuste da absorção indica sensibilidade da planta à capacidade tampão do solo.

Os níveis críticos de fósforo determinados para o $\mathrm{LV}$ e LVA foram de 18,9 e 40,2 $\mathrm{mg} \mathrm{dm}^{-3}$, respectivamente. Bonfim et al. (2004) encontraram correlação significativa entre os níveis críticos de fósforo no solo e o P-remanescente, ou

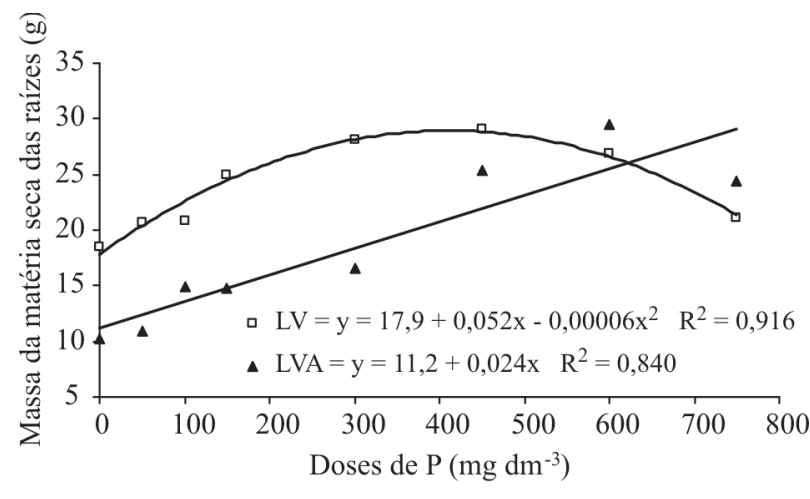

Figura 4 - Massa da matéria seca das raízes de mudas de bananeira Prata anã em função de doses de fósforo aplicadas no LV e LVA. seja, solos com menor valor de P-remanescente tiveram menor valor de nível crítico de fósforo. Verificou-se que o LV teve menor valor de P-remanescente em relação ao LVA (Tabela 1), corroborando os resultados obtidos por Bonfim et al. (2004).

Os níveis críticos de fósforo determinados nas folhas foram de 0,20 e 0,31 dag kg-1, para as mudas cultivadas no LV e LVA, respectivamente. Segundo Silva (1990), o nível crítico de fósforo na parte aérea das plantas eleva-se à medida que o P-remanescente do solo aumenta.

A eficiência de utilização de fósforo pelas mudas de bananeira ajustou-se de forma quadrática com as doses

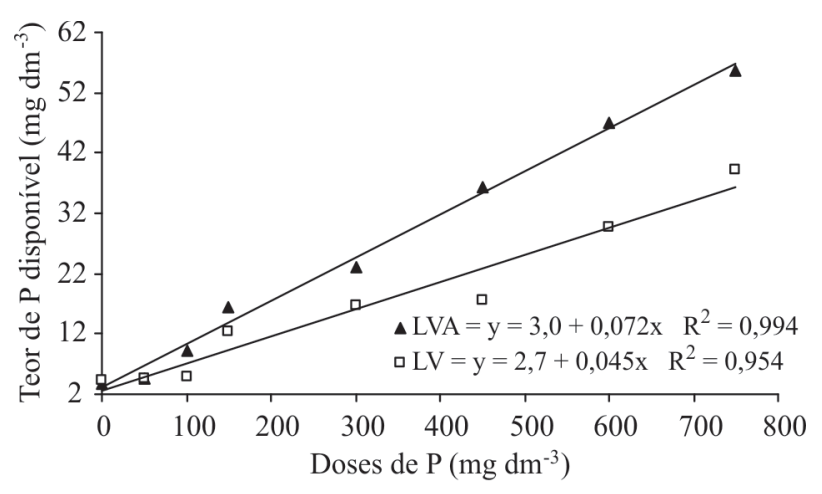

Figura 5 - Teor de fósforo disponível no solo em função de doses de fósforo aplicadas no LV e LVA.

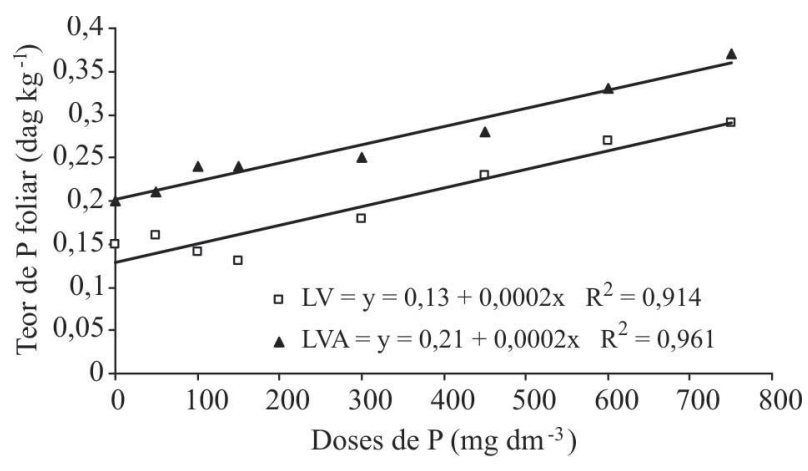

Figura 6 - Teor de fósforo nas folhas de mudas de bananeira Prata anã em função de doses de fósforo aplicadas no LV e LVA.

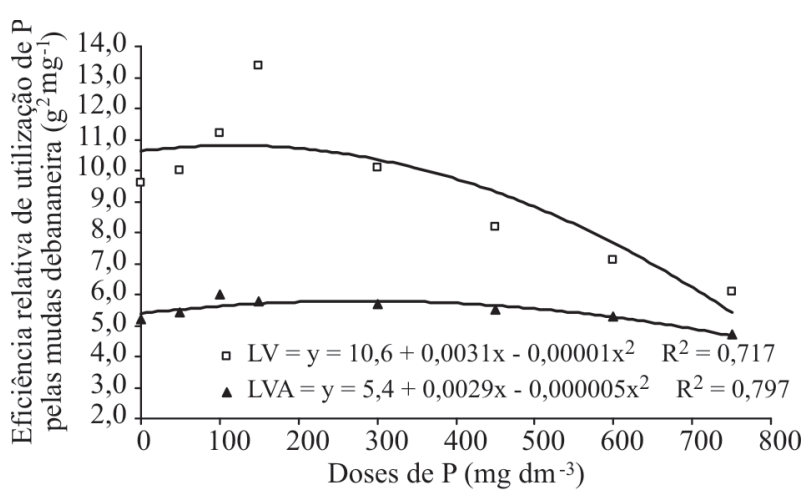

Figura 7 - Eficiência relativa de utilização de P pelas mudas de bananeira Prata anã em função de doses de fósforo aplicadas no LV e LVA.

Rev. Ceres, Viçosa, v. 58, n.1, p. 238-242, mar/abr, 2011 
de fósforo aplicadas nos solos (Figura 7). Verificou-se que as mudas de bananeira foram mais eficientes na utilização do fósforo quando cultivadas no LV de textura argilosa. De acordo com Silva (1990), as plantas, em geral, utilizam com maior eficiência o fósforo quando esse se encontra em menor disponibilidade. Segundo esse autor, o fósforo absorvido em solos argilosos, com elevado fator capacidade tampão, é utilizado com maior eficiência.

As eficiências relativas máximas de utilização de fósforo pelas mudas de bananeira "Prata anã" foram obtidas com as aplicações de 155 e $290 \mathrm{mg} \mathrm{dm}^{-3}$ de fósforo, no LV e LVA, respectivamente. De acordo com Novais et al. (2007), a competição entre a planta e o solo pelo fósforo aplicado como fertilizante faz com que a planta ajuste-se e utilize mais eficientemente o fósforo disponível. Segundo Silva (1990), os níveis críticos de fósforo no solo e na parte aérea das plantas diminuem à medida que aumenta essa competição, a qual se relaciona, de forma inversa, com o P-remanescente.

\section{CONCLUSÕES}

As aplicações de fósforo nos LV e LVA proporcionaram aumentos no desenvolvimento vegetativo das mudas de bananeira.

O nível crítico de fósforo foi menor nas folhas das mudas de bananeira cultivadas no $\mathrm{LV}$, ao passo que no solo foi menor no LV.

As mudas de bananeira utilizaram o fósforo de modo mais eficiente quando cultivadas no LV.

\section{REFERÊNCIAS}

Alvarez V VH (1994) Avaliação da fertilidade do solo. $1^{a}$ ed. Viçosa, Universidade Federal de Viçosa. 75p.

Bedin I, Furtini Neto AE \& Resende AV (2003) Fertilizantes fosfatados e produção da soja em solos com diferentes capacidades tampão de fosfato. Revista Brasileira de Ciência do Solo, 27:639-646.

Bonfim EMS, Freire FJ, Santos MVF, Silva TJA \& Freire MBGS (2004) Níveis críticos de fósforo para Brachiaria brizantha e suas relações com características físicas e químicas em solos de Pernambuco. Revista Brasileira de Ciência do Solo, 28:281-288.

Borges AL \& Oliveira AMG (2000) Nutrição, calagem e adubação. In: Cordeiro, ZJM (Ed.) Banana produção: aspectos técnicos. Brasília, Embrapa Comunicação para transferência de tecnologia. p.47-59.

Braga JM (1980) Avaliação da fertilidade do solo: Análise química. I Parte. Viçosa, Universidade Federal de Viçosa. 87p.

Dechen AR \& Nachtigall GR (2007) Elementos requeridos à nutrição de plantas. In: Novais RF, Alvarez v, VH, Barros NF, Fontes RLF, Cantarutti RB \& Neves, JCL (Eds.) Fertilidade do solo. $1^{\mathrm{a}}$ Ed. Viçosa, Sociedade Brasileira de Ciência do Solo. p.91 - 132.

Furtini Neto AE, Vale FR, Resende AV, Guilherme LRG \& Guedes GAA (2001) Fertilidade do solo. $1^{\text {a }}$ ed. Lavras, ESAL/FAEPE. $252 \mathrm{p}$.

Rev. Ceres, Viçosa, v. 58, n.1, p. 238-242, mar/abr, 2011
Hoffmann RB, Oliveira FHT, Souza AP, Gheyi HR \& Souza Júnior RF (2010) Acúmulo de matéria seca e de macronutrientes em cultivares de bananeira irrigada. Revista Brasileira de Fruticultura, 32:268-275.

Malavolta E \& Vitti CG, Oliveira AS (1997) Avaliação do estado nutricional das plantas: princípios e aplacações. $2^{\text {a }}$ ed. Piracicaba, Potafos. 201p.

Novais RF \& Smyth TJ (1999) Fósforo em solo-planta em condições tropicais. $1^{\mathrm{a}}$ ed. Viçosa, Universidade Federal de Viçosa. $399 \mathrm{p}$.

Novais RF, Smyth TJ \& Nunes FN (2007) Fósforo. In: Novais RF, Alvarez v, VH, Barros NF, Fontes RLF, Cantarutti RB \& Neves, JCL (Eds.) Fertilidade do solo. $1^{\text {a }}$ Ed. Viçosa, Sociedade Brasileira de Ciência do Solo. p.471-550.

Prado RM, Vale DW \& Romualdo LM (2005) Fósforo na nutrição de mudas de maracujazeiro. Acta Scientiarum Agronomy, 27:493498.

Siddiqi MY \& Glass AD (1981) Utilization index: a modified approach to the estimation and comparison of nutrient efficiency in plants, Journal of Plant Nutrition, 4:289-302.

Silva JTA (1990) Relações entre características do solo que refletem a capacidade-tampão de fósforo e o nível crítico para sorgo, em dez Latossolos de Minas Gerais, em casa de vegetação. Dissertação de Mestrado. Universidade Federal de Viçosa, Viçosa. $87 \mathrm{p}$.

Silva JTA, Borges AL \& Malburg JL (1999) Solos, adubação e nutrição da bananeira. Informe agropecuário, 20:21-36.

Silva JTA, Pacheco DD \& Costa EL (2007) Atributos químicos e físicos de solos cultivados com bananeira 'Prata-Anã' (AAB), em três níveis de produtividade, no Norte de Minas Gerais. Revista Brasileira de Fruticultura, 29:102-106.

Sousa HU, Silva CRR, Carvalho GG \& Menegucci JLP (2000) Nutrição de mudas de bananeira em função de substratos e doses de superfosfato simples. Revista Ciência e Agrotecnologia, 24:64-73. 